\section{Proposta de educação alimentar e nutricional integrada ao currículo de Educação Infantil e Ensino Fundamental}

\author{
A proposal for food and nutrition education \\ integrated into the preschool and elementary \\ school curriculum
}

Luciana Maldonado 1 Silvia Cristina Farias 1 Jorginete de Jesus Damião 1 Luciana Maria Cerqueira Castro 1 Ana Carolina Feldenheimer da Silva 1 Inês Rugani Ribeiro de Castro 1

doi: 10.1590/0102-311X00152320

\section{Resumo}

Buscando apoiar iniciativas de educação alimentar e nutricional na escola contínuas e integradas ao currículo, foi elaborada uma série de materiais de apoio para profissionais de educação e de saúde. O artigo apresenta a matriz de temáticas de alimentação e nutrição que serviu de base para a construção destes materiais (Matriz) e apresenta a convergência entre a abordagem adotada nas atividades dos Cadernos de Atividades que compõem a série de materiais e as dimensões da alimentação, os princípios do Marco de Referência de Educação Alimentar e Nutricional para Políticas Públicas (Marco de Educação Alimentar e Nutricional) e as diretrizes curriculares nacionais para a educação básica. A Matriz permitiu a concepção de atividades educativas que oportunizam uma abordagem ampliada sobre alimentação e nutrição e, ao mesmo tempo, transversal e articulada ao currículo. As atividades possibilitaram o diálogo com diferentes componentes curriculares e a articulação entre eles. A convergência das atividades com o Marco de Educação Alimentar e Nutricional se expressou na contextualização das práticas alimentares nos territórios e realidades dos escolares; na abordagem problematizadora, que estimula o pensamento crítico e a promoção de autonomia tanto de educadores como de escolares; e no planejamento intersetorial por meio de temas e estratégias de ação, que encorajam a pactuação entre profissionais de saúde e de educação. Sendo assim, a iniciativa apresentada neste artigo fortalece as ações de educação alimentar e nutricional no âmbito da escola e pode colaborar para a ampliação do repertório dos educadores sobre a temática de alimentação e nutrição e para sua inclusão no currículo de forma cotidiana e transversal.

Comportamento Alimentar; Serviços de Saúde Escolar; Materiais de Ensino

\author{
Correspondência \\ L. Maldonado \\ Universidade do Estado do Rio de Janeiro. \\ Rua São Francisco Xavier 524, Rio de Janeiro, RJ \\ 20550-900, Brasil. \\ luamaldonado71@gmail.com
}

1 Universidade do Estado do Rio de Janeiro, Rio de Janeiro, Brasil. 


\section{Introdução}

A busca pela garantia da saúde e da alimentação como direitos humanos e de cidadania, com ênfase na promoção da alimentação adequada e saudável, tem estimulado a formulação e execução de políticas públicas. No Brasil, a Política Nacional de Alimentação e Nutrição 1 é um marco deste compromisso e tem subsidiado a construção de estratégias e ações como: a elaboração de guias alimentares 2,3, programas 4 , orientação para a organização de serviços e promoção de alimentação adequada e saudável em diferentes espaços 5 . Em várias destas ações e em outras iniciativas, a educação alimentar e nutricional tem sido valorizada como estratégia fundamental para a promoção da alimentação saudável e adequada, e a escola, identificada como espaço privilegiado para a promoção da saúde, por seu potencial na construção do pensamento crítico e da autonomia de todos os membros da comunidade escolar 6,7,8.

Historicamente, a ação do setor saúde na escola tem sido pautada por diferentes concepções e estratégias, variando desde ações centradas no indivíduo, de caráter informativo e normativo e voltadas a mudanças de comportamentos dos estudantes, até práticas pedagógicas em sintonia com os princípios da promoção da saúde, promotoras do pensamento crítico e da autonomia. Cabe ressaltar que estas práticas coexistem nas ações realizadas hoje na escola e sofrem influências da concepção de educação e do conceito de saúde que estejam servindo de base para as ações 9,10.

O Programa Saúde na Escola (PSE) é fruto da parceria entre os setores saúde e educação, e tem como um dos propósitos o desenvolvimento de ações de educação em saúde no ambiente escolar 11. O PSE constitui-se em uma oportunidade para o desenvolvimento de ações de promoção da alimentação adequada e saudável. No entanto, um dos principais desafios para a promoção da alimentação adequada e saudável na escola, é romper com uma perspectiva intervencionista 7 pautada em ações fragmentadas, pontuais e desarticuladas do currículo.

Além do PSE, as ações de educação alimentar e nutricional têm sido impulsionadas por diferentes políticas e estratégias no ambiente escolar. Por exemplo, a Lei 11.947/200912 valorizou as ações de educação alimentar e nutricional na escola, orientando sua articulação ao projeto pedagógico. Diferentes atores são identificados para o desenvolvimento de práticas com esta temática, como professores, cozinheiras escolares, nutricionistas do Programa Nacional de Alimentação Escolar (PNAE) e profissionais de saúde das equipes de atenção primária 4,11,12,13.

Visando apoiar as abordagens sobre alimentação e nutrição no âmbito do PSE, foi produzida uma série de materiais de apoio para profissionais de educação e de saúde atuarem com a comunidade escolar. Essa iniciativa foi fruto da parceria entre o Instituto de Nutrição da Universidade do Estado do Rio de Janeiro (UERJ), a Coordenação-Geral de Alimentação e Nutrição (CGAN) do Ministério da Saúde e a Organização Pan-Americana da Saúde (OPAS). Este artigo tem como objetivos apresentar a matriz de temáticas de alimentação e nutrição por dimensões da alimentação segundo segmento de ensino (Matriz), que serviu de base para construção destes materiais, e apresentar a convergência da abordagem adotada nas atividades dos Cadernos de Atividades (aqui denominados Cadernos) que compõem a série de materiais com as dimensões da alimentação, os princípios do Marco de Referência de Educação Alimentar e Nutricional para Políticas Públicas 6 (Marco de Educação Alimentar e Nutricional) e as diretrizes curriculares nacionais (DCN) para a educação básica.

\section{Referencial teórico}

A abordagem da alimentação exclusivamente sob a ótica biologicista não incorpora outras dimensões necessárias para a construção de respostas adequadas às questões alimentares na atualidade. Uma concepção ampliada considera, além dos aspectos nutricionais e sanitários (dimensão biológica), a sua compreensão como direito humano universal, que deve ser garantido juntamente aos demais direitos para o respeito à vida digna e plena, uma vez que estes são indivisíveis, inter-relacionados e interdependentes (dimensão do direito humano à alimentação adequada); os aspectos simbólicos e afetivos da comida e do comer em sua relação com as pessoas e com a sociedade (dimensão sociopsicocultural); as relações de trabalho e outras questões que envolvem os setores de produção e distribuição de alimentos em sua dinâmica com o mercado econômico (dimensão econômica); além do impacto e da 
sustentabilidade ambiental dos processos de produção, abastecimento e comercialização integrantes dos sistemas alimentares (dimensão ambiental) 14,15.

Assim, as práticas pedagógicas e atividades de educação alimentar e nutricional devem considerar a natureza transversal do tema, a dialogicidade e os aspectos subjetivos relacionados à comida e ao comer. Na trajetória das políticas públicas no Brasil, podemos observar, a partir da década de 1990, uma inflexão da educação alimentar e nutricional como estratégia de promoção de práticas alimentares saudáveis, afinada com novos marcos da promoção da saúde e da educação em saúde, na direção de práticas educativas críticas, compreensivas e emancipadoras, distanciando-se de iniciativas puramente de difusão de informação e mudança de comportamento 6,16.

Um elemento fundamental deste processo de inflexão foi a elaboração do Marco de Educação Alimentar e Nutricional 6, que envolveu diferentes setores do governo e de instituições atuantes na área de alimentação e nutrição do país. Seu objetivo é apoiar as políticas públicas nas ações de educação alimentar e nutricional como estratégia potente para a promoção da alimentação adequada e saudável, baseando-se em um conceito amplo e em princípios inovadores para a sua concretização. O Marco de Educação Alimentar e Nutricional tornou-se referência para a reflexão e a orientação das práticas de educação alimentar e nutricional, apontando a sua natureza transdisciplinar, intersetorial, interprofissional e integrada ao contexto de vida das pessoas. Para isso, indica a necessidade de abordagens pedagógicas inovadoras, problematizadoras e ativas 6 .

As temáticas de alimentação e nutrição apresentam muitas interfaces com outros temas da saúde já incorporados ao currículo e com diversos conteúdos que integram todos os componentes curriculares. O desenvolvimento de ações que sejam articuladas ao currículo, visa expandir a compreensão desta temática e correlacionar o conteúdo do currículo escolar com a multiplicidade de fatores ligados às práticas alimentares.

A Lei de Diretrizes e Bases da Educação Nacional 17 e a Base Nacional Comum Curricular 18, que norteiam os currículos do sistema de educação e propostas pedagógicas das redes de ensino da educação no Brasil, apontam para o compromisso com uma formação humana integral, que considera o sujeito de aprendizagem em sua singularidade, integridade, diversidade e alteridade, visando ao desenvolvimento humano global. Ao realizar a educação alimentar e nutricional, a escola contribui para a construção de conhecimentos e formação de senso crítico sobre a alimentação, uma prática estruturante das relações sociais. Estas características favorecem a promoção da alimentação adequada e saudável na escola, pautada no reconhecimento da alimentação como um direito humano.

\section{Percurso metodológico}

O processo de elaboração da série de materiais (2014-2015) abarcou as etapas descritas a seguir. Inicialmente, foi realizado um levantamento sobre os documentos do Ministério da Educação, orientadores da organização curricular da Educação Infantil e do Ensino Fundamental vigentes à época 19,20,21,22,23,24,25, e sobre os conteúdos de alimentação e nutrição em livros didáticos de 5o a 9o anos do Ensino Fundamental. Em seguida, foi realizada uma oficina de escuta para levantamento de janelas de oportunidade no currículo para se trabalhar temas de alimentação e nutrição. Nela foram também identificadas demandas de abordagens sobre promoção de alimentação adequada e saudável na escola. Ela contou com representantes das redes públicas de saúde e da educação de diferentes estados de todas as regiões do país, membros da CGAN e da OPAS e três pedagogas, sendo uma especializada em ensino infantil e duas, em Ensino Fundamental, que acompanharam todo o projeto.

O produto dessa oficina foi a construção de um quadro por segmento em que foram registrados: oportunidade no currículo (conteúdos segundo componente curricular), tema/conteúdo de alimentação e nutrição, possíveis estratégias pedagógicas e sugestões de leitura sobre o tema. Esses produtos foram aprimorados com base no levantamento descrito anteriormente, realizado pelas autoras com apoio das pedagogas. O resultado desse processo está sistematizado nos Quadros 1 e 2. 
Quadro 1

Conteúdos do currículo escolar da Educação Infantil que dialogam com as dimensões da alimentação. Rio de Janeiro, Brasil, 2014.

\begin{tabular}{|c|c|}
\hline EIXOS DE TRABALHO/FAIXA ETÁRIA (ANOS) & COMPONENTE CURRICULAR \\
\hline \multicolumn{2}{|l|}{ Formação pessoal e social } \\
\hline \multirow[t]{8}{*}{ Até 3} & Autoestima \\
\hline & Escolha \\
\hline & Faz de conta \\
\hline & Interação \\
\hline & Imagem \\
\hline & Segurança \\
\hline & Cuidados \\
\hline & Segurança \\
\hline \multirow[t]{7}{*}{$4-5$} & Nome \\
\hline & Imagem de si/Autoimagem \\
\hline & Independência e autonomia \\
\hline & Interação \\
\hline & Jogos e brincadeiras \\
\hline & Respeito à diversidade \\
\hline & Cuidados pessoais \\
\hline \multicolumn{2}{|l|}{ Conhecimento do mundo } \\
\hline \multirow[t]{5}{*}{ Até 3} & Habilidades - equilíbrio e coordenação \\
\hline & $\begin{array}{c}\text { Falar e escutar } \\
\text { Linguagem }\end{array}$ \\
\hline & $\begin{array}{l}\text { Natureza e sociedade - organização dos grupos e seu modo de ser, viver e } \\
\text { trabalhar; objetos e processos de transformação; os seres vivos }\end{array}$ \\
\hline & Nomeação \\
\hline & Matemática - contagem; números e sistema de numeração \\
\hline \multirow[t]{7}{*}{$4-5$} & Habilidades - equilíbrio e coordenação \\
\hline & Apreciação artística \\
\hline & Linguagem - falar e escutar; leitura e escrita; prática da leitura \\
\hline & $\begin{array}{c}\text { Natureza e sociedade - organização dos grupos e seu modo de ser, viver e } \\
\text { trabalhar; objetos e processos de transformação; os seres vivos }\end{array}$ \\
\hline & Nomeação e classificação \\
\hline & Matemática - operações concretas \\
\hline & Geometria - grandezas e medidas \\
\hline
\end{tabular}

Nota: produto de oficina com especialistas e levantamento, pelas autoras, de documentos orientadores da organização curricular 19,20,21,22 do Ministério da Educação.

Fonte: elaborado pelas autoras (2020). 
Quadro 2

Conteúdos do currículo escolar do Ensino Fundamental que dialogam com as dimensões da alimentação. Rio de Janeiro, Brasil, 2014.

\begin{tabular}{|c|c|c|c|c|}
\hline \multirow[t]{3}{*}{ COMPONENTE CURRICULAR } & \multicolumn{4}{|c|}{ SEGMENTO } \\
\hline & \multicolumn{2}{|c|}{$\begin{array}{l}\text { ENSINO FUNDAMENTAL I } \\
\text { (ANOS INICIAIS) }\end{array}$} & \multicolumn{2}{|c|}{$\begin{array}{l}\text { ENSINO FUNDAMENTAL II } \\
\text { (ANOS FINAIS) }\end{array}$} \\
\hline & 1o CICLO & 20 CICLO & 3o CICLO & 40 CICLO \\
\hline Língua portuguesa & \multicolumn{2}{|c|}{$\begin{array}{l}\text { - Entendimento, aprendizagem e uso dos } \\
\text { códigos: letras, palavras, números, sinais } \\
\text { - Gêneros textuais } \\
\text { - Fatores de coerência textual: Aprendizado } \\
\text { inicial e prática de leitura, prática de produção } \\
\text { de textos, revisão de texto, aprendendo com } \\
\text { textos, alfabetização, ortografia, pontuação, } \\
\text { aspectos gramaticais }\end{array}$} & \multicolumn{2}{|c|}{$\begin{array}{l}\text { - Conceitos e procedimentos subjacentes às práticas de } \\
\text { linguagem: prática de escuta de textos orais e leitura de } \\
\text { textos escritos, prática de produção de textos orais e } \\
\text { escritos } \\
\text { - Valores e atitudes subjacentes às práticas de linguagem } \\
\text { (posicionamento crítico diante de texto, interesse, iniciativa } \\
\text { e autonomia para ler textos diversos; interesse pela leitura, } \\
\text { escrita como fonte de informação, aprendizagem de lazer } \\
\text { e arte) } \\
\text { - Prática de produção de textos orais e escritos: produção } \\
\text { de textos orais, produção de textos escritos }\end{array}$} \\
\hline Matemática & \multicolumn{2}{|c|}{$\begin{array}{l}\text { - Números naturais e sistema de numeração } \\
\text { decimal } \\
\text { - Operações com números naturais } \\
\text { - Espaço e forma } \\
\text { - Grandezas e medidas } \\
\text { - Tratamento da Informação (tabelas e gráficos) }\end{array}$} & $\begin{array}{c}\text { - Problemas envolvendo } \\
\text { números naturais, } \\
\text { inteiros, racionais, que } \\
\text { envolvam diferentes } \\
\text { grandezas, selecionando } \\
\text { unidades de medida e } \\
\text { instrumentos adequados } \\
\text { à precisão requerida e } \\
\text { a partir delas ampliar } \\
\text { e construir novos } \\
\text { significados da adição, } \\
\text { subtração, multiplicação, } \\
\text { divisão, potenciação, } \\
\text { radiciação; interpretações } \\
\text { algébricas como } \\
\text { tradução de situações } \\
\text { problema; construção } \\
\text { e interpretação de } \\
\text { tabelas e gráficos; } \\
\text { proporcionalidade. }\end{array}$ & $\begin{array}{l}\text { - Diferentes procedimentos } \\
\text { de cálculo com números } \\
\text { naturais, inteiros, racionais e } \\
\text { irracionais; leis matemáticas } \\
\text { que expressem a relação de } \\
\text { dependência entre as variáveis; } \\
\text { noções de medidas, cálculos e } \\
\text { aproximação de resultados de } \\
\text { acordo com o grau de precisão } \\
\text { desejado; problemas que } \\
\text { envolvam relações de grandeza } \\
\text { direta ou inversamente } \\
\text { proporcionais; tabelas de } \\
\text { frequências e gráficos de dados } \\
\text { estatísticos }\end{array}$ \\
\hline História & \begin{tabular}{|} 
- Identidade (pessoal, \\
familiar e social) \\
- Cidadania, \\
solidariedade e \\
respeito \\
- Datas \\
comemorativas
\end{tabular} & $\begin{array}{l}\text { - Identidade (pessoal, } \\
\text { familiar e social) } \\
\text { - Cidadania, } \\
\text { solidariedade e respeito } \\
\text { - Envolvimento da } \\
\text { família }\end{array}$ & $\begin{array}{l}\text { - História das relações } \\
\text { sociais, da cultura e do } \\
\text { trabalho: as relações } \\
\text { sociais, a natureza e a } \\
\text { terra } \\
\text { - As relações de trabalho }\end{array}$ & $\begin{array}{l}\text { - História das representações } \\
\text { e das relações de poder: } \\
\text { Nações, povos, lutas, guerras e } \\
\text { revoluções; cidadania e cultura } \\
\text { no mundo contemporâneo }\end{array}$ \\
\hline
\end{tabular}

(continua) 


\begin{tabular}{|c|c|c|c|c|}
\hline \multirow[t]{3}{*}{ COMPONENTE CURRICULAR } & \multicolumn{4}{|c|}{ SEGMENTO } \\
\hline & \multicolumn{2}{|c|}{$\begin{array}{l}\text { ENSINO FUNDAMENTAL I } \\
\text { (ANOS INICIAIS) }\end{array}$} & \multicolumn{2}{|c|}{$\begin{array}{l}\text { ENSINO FUNDAMENTAL II } \\
\text { (ANOS FINAIS) }\end{array}$} \\
\hline & 10 CICLO & 20 CICLO & 3ㅇ CICLO & 4으 CICLO \\
\hline Geografia & $\begin{array}{l}\text { - Elementos naturais } \\
\text { (água, ar, solo) e } \\
\text { culturais (transporte, } \\
\text { habitação, indústria); } \\
\text { - Ecossistema; } \\
\text { - Poluição e } \\
\text { contaminação da } \\
\text { água, agrotóxicos, } \\
\text { uso de herbicidas e } \\
\text { inseticidas }\end{array}$ & $\begin{array}{l}\text { - Órgãos responsáveis } \\
\text { pela fiscalização } \\
\text { (ex.: ANVISA, INEA); } \\
\text { responsabilidade do } \\
\text { Estado; } \\
\text { - Ecossistema; } \\
\text { - Poluição e } \\
\text { contaminação da água, } \\
\text { agrotóxicos, uso de } \\
\text { herbicidas e inseticidas }\end{array}$ & $\begin{array}{c}\text { - A construção do espaço: } \\
\text { os territórios e os lugares } \\
\text { (o tempo da sociedade e } \\
\text { o tempo da natureza); a } \\
\text { conquista do lugar como } \\
\text { conquista da cidadania; } \\
\text { a natureza e as questões } \\
\text { socioambientais } \\
\text { - A modernização } \\
\text { capitalista e a redefinição } \\
\text { das relações entre o } \\
\text { campo e a cidade } \\
\text { - A cultura e consumo: } \\
\text { uma nova interação entre } \\
\text { o campo e a cidade; os } \\
\text { mapas como possibilidade } \\
\text { de compreensão e } \\
\text { estudos comparativos das } \\
\text { diferentes paisagens e } \\
\text { lugares }\end{array}$ & $\begin{array}{l}\text { - A globalização e as } \\
\text { hierarquias urbanas; } \\
\text { Estado, povos e nações } \\
\text { redesenhando as fronteiras; } \\
\text { paisagens e diversidade } \\
\text { territorial no Brasil; } \\
\text { - Alimentar o mundo: os } \\
\text { dilemas socioambientais para a } \\
\text { segurança alimentar. } \\
\text { - Ambiente urbano, indústria e } \\
\text { modo de vida; } \\
\text { - O Brasil diante das questões } \\
\text { ambientais; } \\
\text { - Ambientalismo: pensar e agir. }\end{array}$ \\
\hline Ciências & \multicolumn{2}{|c|}{$\begin{array}{l}\text { - Cadeia alimentar (produção, distribuição, } \\
\text { comercialização e consumo); } \\
\text { - Meio ambiente: compostagem, orgânico e } \\
\text { inorgânico, destino de resíduos }\end{array}$} & \multicolumn{2}{|c|}{$\begin{array}{l}\text { - Terra e universo } \\
\text { - Vida e ambiente } \\
\text { - Ser humano e saúde } \\
\text { - Tecnologia e sociedade }\end{array}$} \\
\hline Arte & & & $\begin{array}{l}\text { Artes visuais } \\
\text { - Teatro } \\
\text { - Dança } \\
\text { - Música }\end{array}$ & \\
\hline Educação Física & & $\begin{array}{l}\text { - Conhe } \\
\text { - Esportes } \\
\text { - Atividad }\end{array}$ & $\begin{array}{l}\text { imento sobre o corpo } \\
\text { jogos, lutas e ginásticas } \\
\text { s rítmicas e expressivas }\end{array}$ & \\
\hline
\end{tabular}

ANVISA: Agência Nacional de Vigilância Sanitária; INEA: Instituto Estadual do Ambiente.

Nota: produto de oficina com especialistas e levantamento, pelas autoras, de documentos orientadores da organização curricular 23,24,25 do Ministério da Educação.

Fonte: elaborado pelas autoras (2020).

Finalizada a primeira versão das atividades que comporiam os materiais educativos, foi realizada nova oficina de escuta que envolveu docentes e pesquisadores em educação alimentar e nutricional e profissionais da rede pública de saúde (nutricionistas, médicos, enfermeiros e psicólogos) e de educação (professores e coordenadores pedagógicos da Educação Infantil aos anos finais do Ensino Fundamental). Eles foram convidados a opinar sobre a adequação da linguagem e do conteúdo das atividades, bem como de seu potencial para proporcionar o diálogo entre saúde e educação. Os produtos dessa oficina subsidiaram a etapa final, que abarcou: conclusão da elaboração das atividades, concepção e produção de vídeos de apoio aos Cadernos e elaboração de livreto sobre promoção de alimentação adequada e saudável em creches voltado a gestores de saúde e educação. A descrição 
do conjunto de materiais que compõem a série está apresentada no Quadro 3. Tanto o diálogo com parceiros quanto o processo de desenvolvimento dos materiais foram permeados pelo compromisso com a viabilidade de implementação das atividades sugeridas.

Os Quadros 1 e 2 serviram de base para a elaboração da matriz de temáticas de alimentação e nutrição por dimensões da alimentação segundo segmento de ensino cujo conteúdo será apresentado na seção de Resultados e Discussão. Esta elaboração se deu por meio de processo reflexivo, realizado pelas autoras, sobre as interseções entre aspectos centrais das dimensões de alimentação e conteúdos previstos no currículo escolar. A Matriz foi utilizada para nortear a abordagem de alimentação e nutrição em todos os materiais que compõem a série, tendo orientado o trabalho dos participantes da

\section{Quadro 3}

Materiais produzidos para Promoção da Alimentação Adequada e Saudável no âmbito do Programa Saúde na Escola (PSE). Rio de Janeiro, Brasil, 2019.

\begin{tabular}{|c|c|}
\hline MATERIAL & DESCRIÇÃO \\
\hline $\begin{array}{l}\text { Caderno de Atividades para a Promoção da Alimentação Adequada e } \\
\text { Saudável: Educação Infantil (92p). } \\
\text { Blocos de Atividades: A Criança e Seu Corpo; A Criança e Os Alimentos; } \\
\text { Vivendo e Comendo. } \\
\text { Disponível em: http://189.28.128.100/dab/docs/portaldab/publicacoes/ } \\
\text { caderno_atividades_educacao_infantil.pdf }\end{array}$ & \multirow[t]{3}{*}{$\begin{array}{l}\text { Dirigido a professores e profissionais de saúde. Visa à valorização da } \\
\text { transversalidade do tema alimentação e nutrição, em suas diferentes } \\
\text { dimensões, e a sua convergência com as diretrizes curriculares. } \\
\text { Contém uma breve abordagem teórica, sugestões de atividades, com } \\
\text { identificação de componentes curriculares trabalhados, e de materiais } \\
\text { complementares. }\end{array}$} \\
\hline $\begin{array}{l}\text { Caderno de Atividades para a Promoção da Alimentação Adequada e } \\
\text { Saudável: Ensino Fundamental I (127p). } \\
\text { Blocos de Atividades: A Criança, Os Alimentos e A Alimentação no Curso } \\
\text { da Vida; Alimentação Como Prática Social; Sistema Alimentar. } \\
\text { Disponível em: http://189.28.128.100/dab/docs/portaldab/publicacoes/ } \\
\text { caderno_atividades_ensino_fundamental_I.pdf }\end{array}$ & \\
\hline $\begin{array}{l}\text { Caderno de Atividades para a Promoção da Alimentação Adequada e } \\
\text { Saudável: Ensino Fundamental II (135p). } \\
\text { Blocos de Atividades: Alimentação no Contexto Contemporâneo; } \\
\text { Sistema Alimentar. } \\
\text { Disponível em: http://bvsms.saude.gov.br/bvs/publicacoes/promocao_ } \\
\text { alimentacao_saudavel_ensino_fundamental_Il.pdf }\end{array}$ & \\
\hline $\begin{array}{l}\text { A Creche como Promotora da Amamentação e Alimentação Adequada e } \\
\text { Saudável: Livreto para Os Gestores (36p). } \\
\text { Disponível em: http://189.28.128.100/dab/docs/portaldab/ } \\
\text { publicacoes/a_creche_promotora_amamentacao_livreto_gestores.pdf }\end{array}$ & $\begin{array}{l}\text { Dirigido a gestores da Saúde e da Educação. Visa à sensibilização } \\
\text { e orientação para a promoção da amamentação e da alimentação } \\
\text { adequada e saudável em unidades escolares de educação infantil. }\end{array}$ \\
\hline $\begin{array}{l}\text { Vídeo: Os Caminhos da Comida }\left(16^{\prime} 23^{\prime \prime}\right) \\
\text { Disponível em: https://www.youtube.com/watch?v=BYw0EVdQbV8 }\end{array}$ & $\begin{array}{l}\text { Dirigido a professores e profissionais da saúde. Aborda as dimensões } \\
\text { da alimentação e os componentes do sistema alimentar; e valoriza a } \\
\text { escola como espaço fundamental para a promoção da alimentação } \\
\text { adequada e saudável, apresentando os materiais da série. }\end{array}$ \\
\hline $\begin{array}{l}\left.\text { Vídeo: Nico e o Tubérculo ( } 11^{\prime} 57^{\prime \prime}\right) \\
\text { Disponível em: https://www.youtube.com/watch?v=biq3xE303Zc\&t=71s }\end{array}$ & $\begin{array}{l}\text { Dirigido a estudantes do Ensino Fundamental I (anos iniciais). Aborda } \\
\text { os temas grupos de alimentos, alimentos regionais, comensalidade } \\
\text { e culinária por meio da história de Nico, um menino que descobre o } \\
\text { valor da cultura alimentar de sua família quando realiza uma atividade } \\
\text { escolar. }\end{array}$ \\
\hline $\begin{array}{l}\text { Vídeo: Sem Cantina! }\left(12^{\prime} 52^{\prime \prime}\right) \\
\text { Disponível em: https://www.youtube.com/ } \\
\text { watch?v=4QI6nOxbyKI\&t=322s }\end{array}$ & $\begin{array}{l}\text { Dirigido a estudantes do Ensino Fundamental Il (anos finais). Aborda } \\
\text { os temas de alimentos ultraprocessados, mídia, regulação das cantinas } \\
\text { escolares e culinária por meio da história de dois adolescentes que } \\
\text { realizam uma investigação após o fechamento da cantina escolar. }\end{array}$ \\
\hline
\end{tabular}

Fonte: elaborado pelas autoras (2020). 
segunda oficina de especialistas. Uma vez elaboradas as atividades, voltamos à Matriz para nos certificarmos de que todas as temáticas de alimentação e nutrição haviam sido contempladas.

Para atender o primeiro objetivo deste artigo, a Matriz é apresentada juntamente com uma reflexão sobre a perspectiva ampliada de alimentação que ela oportuniza e sobre seu potencial organizador de uma abordagem transversal sobre alimentação e nutrição desde a Educação Infantil até os anos finais do Ensino Fundamental.

Para atender o segundo objetivo, conteúdos, abordagens, estratégias educativas e objetivos das atividades dos Cadernos foram cotejados com as dimensões da alimentação, com as DCN e com os princípios do Marco de Educação Alimentar e Nutricional. Tendo em vista a centralidade desses princípios para a qualificação das práticas educativas, esse último cotejamento foi complementado com uma sistematização do número de atividades propostas por princípio do Marco de Educação Alimentar e Nutricional e com exemplos de como cada princípio foi nelas abordado.

O detalhamento desses cotejamentos está sistematizado em dois materiais suplementares: o primeiro traz as atividades propostas nos Cadernos, seus objetivos e suas interfaces com as dimensões da alimentação, componentes curriculares e princípios do Marco de Educação Alimentar e Nutricional (Material Suplementar. Quadro S1. http://cadernos.ensp.fiocruz.br/static//arquivo/ suppl-e00152320-s1_6178.pdf); e o segundo apresenta um exercício de articulação das temáticas de alimentação e nutrição com os conteúdos e componentes curriculares levantados na primeira oficina de escuta e/ ou adotados nos Cadernos por dimensões de alimentação e segmento escolar (Material Suplementar. Quadro S2. http://cadernos.ensp.fiocruz.br/static//arquivo/supple00152320-s2_9233.pdf).

\section{Resultados e discussão}

\section{As dimensões da alimentação na Matriz e nas atividades dos Cadernos}

A Matriz de temáticas de alimentação e nutrição por dimensões da alimentação e por segmentos de ensino está apresentada no Quadro 4.

O primeiro ponto de reflexão é a abordagem ampliada sobre alimentação e nutrição na escola que a Matriz oportuniza. Análises de livros didáticos e de práticas de educação alimentar e nutricional na escola indicam que esta temática é frequentemente apresentada à comunidade escolar com foco em aspectos nutricionais e sanitários, reduzindo a alimentação e nutrição à sua dimensão biológica 26,27,28. Ao adotar as dimensões da alimentação como referencial teórico, foi possível o diálogo com componentes curriculares antes ausentes ou secundarizados, como História e Geografia, favorecendo a contextualização das práticas alimentares nos territórios e ao longo dos processos históricos relacionados às mudanças e às permanências nos diferentes contextos de vida.

Buscou-se, ainda, abordar a dimensão biológica da alimentação de forma a superar uma visão idealizada e/ou medicalizante do alimento e o foco na prevenção e tratamento de doenças 29. Procurou-se, também, reconhecer a articulação desta dimensão com as demais: nas atividades propostas, partindo dos princípios do Guia Alimentar para a População Brasileira e da classificação de alimentos NOVA, os aspectos nutricionais e sanitários foram problematizados, levando-se em conta os impactos das escolhas alimentares na saúde, na cultura e no meio ambiente 2,30. As abordagens educativas baseadas nesta classificação têm se mostrado mais efetivas do que as tradicionais 31 .

Esse enfoque ampliado pode também ser observado em conteúdos propostos pela Matriz e desdobrados nas atividades, com destaque para: o direito humano para a alimentação adequada 32 , a amamentação ${ }^{3}$ e o sistema alimentar 33 nos três segmentos de ensino; o cuidado com o corpo 18 e a culinária 34 na Educação Infantil; a classificação de alimentos segundo a extensão e o propósito de processamento 2 , a alimentação regional 35 e a comensalidade 36 nos anos iniciais do Ensino Fundamental (Ensino Fundamental I); e a soberania alimentar 37, a imagem corporal 38, os aspectos contemporâneos da alimentação, com destaque para as questões de gênero 39 e consumismo 40 nos anos finais do Ensino Fundamental (Ensino Fundamental II) (Material Suplementar. Quadro S1. http://cadernos. ensp.fiocruz.br/static//arquivo/suppl-e00152320-s1_6178.pdf; Material Suplementar. Quadro S2. http://cadernos.ensp.fiocruz.br/static//arquivo/suppl-e00152320-s2_9233.pdf). 
Quadro 4

Matriz de temáticas de alimentação e nutrição por dimensões da alimentação e por segmentos de ensino. Rio de Janeiro, Brasil, 2019.

\begin{tabular}{|c|c|c|c|}
\hline DIMENSÕES & EDUCAÇÃO INFANTIL & $\begin{array}{l}\text { ENSINO FUNDAMENTAL I } \\
\text { (ANOS INICIAIS) }\end{array}$ & $\begin{array}{l}\text { ENSINO FUNDAMENTAL II } \\
\text { (ANOS FINAIS) }\end{array}$ \\
\hline $\begin{array}{l}\text { Direito humano à alimentação } \\
\text { adequada }\end{array}$ & $\begin{array}{l}\text { - Direito de comer e de beber } \\
\text { água limpa }\end{array}$ & $\begin{array}{l}\text { - Alimentação e noção de } \\
\text { direito e cidadania } \\
\text { - Acesso aos alimentos }\end{array}$ & $\begin{array}{c}\text { - Segurança alimentar e nutricional } \\
\text { (alimentação como direito ou } \\
\text { mercadoria; papel do Estado; } \\
\text { políticas públicas; alimentação } \\
\text { escolar como direito; desigualdades; } \\
\text { equidade) } \\
\text { - Soberania Alimentar }\end{array}$ \\
\hline Biológica & $\begin{array}{c}\text { - Reconhecimento dos } \\
\text { alimentos (água) } \\
\text { - Corpo (cuidado, crescimento) } \\
\text { - Imagem corporal } \\
\text { - Características sensoriais }\end{array}$ & $\begin{array}{l}\text { - Grupos de alimentos/ } \\
\text { classificação de alimentos de } \\
\text { acordo com o processamento } \\
\text { - Comer no curso da vida } \\
\text { - Metabolismo: alimentos e } \\
\text { nutrientes } \\
\text { - Higiene e alimentos } \\
\text { - Água como alimento }\end{array}$ & $\begin{array}{l}\text { - Classificação dos alimentos de } \\
\text { acordo com processamento } \\
\text { - Corpo e alimentação (subjetividade) }\end{array}$ \\
\hline Sociopsicocultural & $\begin{array}{l}\text { - Culinária } \\
\text { - Comensalidade } \\
\text { - Amamentação }\end{array}$ & $\begin{array}{l}\text { - Hábitos e costumes } \\
\text { alimentares de famílias de } \\
\text { regiões e de sociedades } \\
\text { - Alimentação ao longo do } \\
\text { tempo } \\
\text { - Culinária e comensalidade } \\
\text { - Amamentação } \\
\text { - Mídia e consumo }\end{array}$ & $\begin{array}{l}\text { - Escolhas alimentares } \\
\text { - Alimentação e contemporaneidade } \\
\text { (comensalidade, tempo, } \\
\text { globalização, mudança nos padrões } \\
\text { alimentares, culinária e gênero) } \\
\text { - Amamentação } \\
\text { - Mídia e consumo }\end{array}$ \\
\hline Econômica & $\begin{array}{l}\text { - Profissões ligadas ao sistema } \\
\text { alimentar } \\
\text { - Desperdício de alimentos }\end{array}$ & $\begin{array}{l}\text { - Profissões no sistema } \\
\text { alimentar } \\
\text { - Disponibilidade e acesso a } \\
\text { alimentos } \\
\text { - Produção, armazenamento, } \\
\text { transporte e comércio de } \\
\text { alimentos }\end{array}$ & $\begin{array}{c}\text { - Relações de trabalho no sistema } \\
\text { alimentar }\end{array}$ \\
\hline Ambiental & $\begin{array}{l}\text { - Origem dos alimentos } \\
\text { - Higiene }\end{array}$ & $\begin{array}{r}\text { - Produção } \\
\text { - Desperdício em todas } \\
\text { - Sistema alimentar (produção, } \\
\text { agricultura, meio ambiente, } \\
\text { destir } \\
\text { - Impactos da }\end{array}$ & $\begin{array}{l}\text { estino de resíduos } \\
\text { etapas do sistema alimentar } \\
\text { nercialização, consumo de alimentos, } \\
\text { a, desperdício em todas as etapas, } \\
\text { de resíduos) } \\
\text { scolhas alimentares }\end{array}$ \\
\hline
\end{tabular}

Fonte: elaborado pelas autoras (2019).

O segundo ponto de reflexão é o da Matriz como organizadora de uma abordagem transversal sobre alimentação e nutrição ao longo dos segmentos escolares. Isso se expressa em um gradiente de complexificação de como determinado tema é tratado tanto na Matriz como nas atividades propostas, permitindo o aprofundamento da discussão de acordo com o desenvolvimento da criança e com a organização curricular. Por exemplo, o direito humano para a alimentação adequada 32 é explorado como um dos direitos das crianças juntamente com brincar e estudar na Educação Infantil; como a noção de direito humano no Ensino Fundamental I; e como direito a ser garantido pelo Estado 
no Ensino Fundamental II. Já o sistema alimentar 33 é enfocado na Educação Infantil por meio das profissões a ele relacionadas; da identificação de seus principais componentes (cadeia alimentar, sistemas alimentares e práticas alimentares) no Ensino Fundamental I; e pela discussão das relações de trabalho estabelecidas neste sistema no Ensino Fundamental II (Quadro 4). Essa abordagem transversal oferecida pela Matriz e materializada nas atividades propostas nos Cadernos favorece concepções e práticas de promoção da alimentação adequada e saudável sensíveis ao currículo e a ele articuladas 12 (Material Suplementar. Quadro S2. http://cadernos.ensp.fiocruz.br/static//arquivo/ suppl-e00152320-s2_9233.pdf) possibilitando, ainda a integração do tema da alimentação e nutrição ao projeto político pedagógico de cada escola.

De forma geral, todos os temas de alimentação e nutrição previstos na Matriz foram abordados nas atividades com maior ou menor grau de centralidade. Estes temas podem ser os conteúdos principais da atividade; podem estar presentes em aspectos a serem aprofundados de acordo com cada grupo de estudantes; ou, ainda, constarem nos materiais educativos sugeridos para apoiar o desenvolvimento das atividades.

\section{As atividades dos Cadernos e os componentes curriculares}

As atividades possibilitaram um diálogo com diferentes componentes curriculares (Material Suplementar. Quadro S1. http://cadernos.ensp.fiocruz.br/static//arquivo/suppl-e00152320-s1_6178.pdf). Para a Educação Infantil, componentes abarcados pelos eixos de "formação pessoal e social" e "natureza e sociedade" foram abordados no conjunto das atividades propostas; e todos aqueles do Ensino Fundamental foram contemplados em cada um dos dois segmentos, com exceção de educação física para o Ensino Fundamental I.

Além disso, a concepção das atividades também favoreceu a articulação entre diferentes componentes curriculares, possibilitando uma abordagem integral do conhecimento 18. No Ensino Fundamental I, as atividades envolveram de dois a seis componentes, sendo mais frequentes aquelas que abarcaram três ou quatro. No Ensino Fundamental II, elas abordaram de três a cinco componentes, sendo mais recorrentes aquelas que contemplaram três. Este esforço de diálogo com os componentes curriculares e de articulação entre eles configura um avanço para a prática de educação alimentar e nutricional.

Na Educação Infantil, a oralidade, a psicomotricidade e o conhecimento de si e do outro são características do desenvolvimento infantil que apresentam um diálogo intenso com as práticas alimentares. Considerando a criança como sujeito - histórico e de direitos - que constrói sua identidade, os eixos estruturantes das práticas pedagógicas são as interações e a brincadeira. Nesta fase, educar e cuidar são concepções associadas ao processo educativo e as vivências na escola; a família e a comunidade serão a base para o aprendizado de socialização, autonomia e comunicação 18. Assim, as atividades do Caderno de Educação Infantil possuem como características centrais a ludicidade, o estímulo à autonomia e ao autocuidado e o envolvimento da família.

O Ensino Fundamental, que abrange nove anos da vida escolar, abarca a transição da Educação Infantil para o Ensino Fundamental I, a mudança entre professores generalistas e especialistas e a transição para o Ensino Médio. Ao longo do Ensino Fundamental I, as vivências pedagógicas iniciadas na Educação Infantil vão se consolidando e organizando o processo de alfabetização.

A ludicidade continua presente, as interações com o mundo se ampliam e, de forma progressiva, o raciocínio lógico se desenvolve. Em um processo dinâmico entre a criança e os coletivos de que participa, a autonomia se desenvolve, assim como o uso de múltiplas linguagens para a construção e a expressão de novos conhecimentos 18. As atividades propostas no Caderno dirigido ao Ensino Fundamental I estão baseadas no raciocínio lógico e no estímulo ao desenvolvimento da oralidade, mantendo os aspectos lúdicos e recorrendo aos usos sociais da escrita e da matemática para construir conhecimentos sobre alimentação e nutrição. São oferecidas oportunidades para exercitar a observação, a percepção, a análise, a representação e as descobertas. As atividades são adaptadas às diferentes necessidades e capacidades de mobilização das operações cognitivas.

Em um processo contínuo de ampliação de práticas pedagógicas mediadas pelas relações entre os sujeitos e a natureza, a história, a tecnologia e o ambiente, ocorre a transição para o Ensino Fundamental II. Esse é um período com maior complexidade cognitiva, especialização das áreas de conhe- 
cimento e interação crítica com diferentes fontes de informação. O raciocínio abstrato e a capacidade de se colocar no lugar do outro contribuem para o fortalecimento da autonomia e a construção de valores morais e éticos. Essa transição acompanha a passagem da infância para a adolescência; por isso, compreender as diferentes formas de adolescer e como se expressam as múltiplas juventudes é fundamental para propor ações educativas contextualizadas e dialógicas 18. O Caderno dirigido ao Ensino Fundamental II propõe atividades que valorizam o senso crítico característico desta faixa etária e priorizam a capacidade de argumentação como forma de contribuir para a participação cidadã na sociedade, como o debate sobre a relação entre fome e pobreza e a promoção da alimentação adequada e saudável. As atividades propõem diferentes formas de expressão e de pesquisa usando as tecnologias de informação e comunicação, buscando contribuir para um diálogo entre o imediatismo do mundo contemporâneo e a necessidade de reflexões mais profundas sobre as questões de alimentação e nutrição destes estudantes.

No Ensino Fundamental, a organização curricular por componentes que integram as áreas de conhecimento (Linguagens, Matemática, Ciências da Natureza e Ciências Humanas) torna-se mais desafiadora para uma abordagem sobre alimentação e nutrição que promova a articulação entre esses componentes. Por exemplo, na atividade A Cozinha Ontem e Hoje, o diálogo com os componentes curriculares se deu da seguinte forma: com Língua Portuguesa, por estimular o registro de forma textual de comparações entre características de alimentação do estudante e de familiares mais velhos; com História, por explorar as mudanças e as permanências nos hábitos e práticas alimentares ao longo do tempo; com Matemática, pela estruturação de quadros para resumo quantitativo das informações coletadas; com Geografia, pelo levantamento de alimentos consumidos nos territórios dos estudantes; com Ciências, pela discussão sobre hábitos alimentares saudáveis; e com Artes, pela possibilidade de customização dos quadros propostos e das formas de expressão da sistematização das informações coletadas.

Em grande parte das vezes, o conteúdo proposto nos parâmetros e nas DCN para cada segmento foi utilizado como base para o desenvolvimento da atividade. Por exemplo, "identidade pessoal, familiar e social" e "valorização da cultura local" foram as bases para atividades que se conectam ao componente de Língua Portuguesa (ex.: atividade Conhecendo Nossas Práticas Alimentares) e de Geografia (ex.: atividade Sabores da Nossa Terra) no Ensino Fundamental I. No Ensino Fundamental II, os conteúdos "autoestima e diversidade" e "identidades e beleza" embasaram as atividades que articulam os componentes de História, Geografia, Língua Portuguesa, Ciências e Educação Física (ex.: atividade Imagem Corporal I: Identidade Coletiva e Diversidade e atividade Imagem Corporal II: Identidade Individual e Autoestima).

\section{As atividades dos Cadernos e os princípios do Marco de Educação Alimentar e Nutricional}

Tanto a Matriz quanto o conjunto das atividades propostas convergem com todos os princípios do Marco de Educação Alimentar e Nutricional, que vão ganhando contornos específicos de abordagem em cada um dos segmentos em função do desenvolvimento da criança e da organização do cotidiano escolar (Quadro 4 e Material Suplementar. Quadro S1. http://cadernos.ensp.fiocruz.br/static// arquivo/suppl-e00152320-s1_6178.pdf). Esta convergência se expressou na contextualização das práticas alimentares nos territórios e realidades dos escolares; na abordagem problematizadora, que estimula o pensamento crítico e a promoção de autonomia tanto de educadores como de escolares; e no planejamento intersetorial por meio de temas e estratégias de ação, que encorajam a pactuação entre profissionais de saúde e de educação.

O Quadro 5 apresenta uma sistematização do número de atividades propostas nos Cadernos que abordam cada princípio do Marco de Educação Alimentar e Nutricional e exemplifica de que forma o princípio foi abordado em atividades para cada segmento.

Na Educação Infantil a promoção do autocuidado e da autonomia (princípio V) - assim como a participação ativa e informada dos sujeitos (princípio VI) - são os mais abordados. As atividades valorizam a relação da criança com o seu corpo, a exploração das características sensoriais dos alimentos e a percepção das relações entre o alimento e as práticas sociais. Estes aspectos favorecem o aprendizado de forma geral, a construção de uma relação positiva da criança com a comida e a formação de hábitos alimentares saudáveis. 
Nas atividades para o Ensino Fundamental I prevalecem os princípios de valorização da cultura alimentar local e respeito aos saberes de diferentes naturezas (princípio III), a comida como referência e a valorização da culinária enquanto prática emancipatória (princípio IV), e a promoção do autocuidado e da autonomia (princípio V). O diálogo com esses princípios possibilita o reconhecimento da pluralidade de práticas alimentares presentes nas diferentes culturas do povo brasileiro, dado que o foco das atividades propostas está na comida, no entendimento de que ela faz parte do cotidiano e nas reflexões sobre as próprias práticas alimentares ao longo do curso da vida. Além desse diálogo, também foi frequente a articulação com os princípios de sustentabilidade social, ambiental e econômica (princípio I) e da abordagem do sistema alimentar, na sua integralidade (princípio II) por meio da articulação com os diversos componentes do sistema alimentar, da exploração do território em que os estudantes vivem e da identificação dos atores envolvidos nos processos de produção e comercialização dos alimentos.

Nas atividades para o Ensino Fundamental II prevalecem os princípios de sustentabilidade social, ambiental e econômica (princípio I), valorização da cultura alimentar local e respeito aos saberes de diferentes naturezas (princípio III) e a promoção do autocuidado e da autonomia (princípio V). Sua articulação se estabelece por meio das discussões sobre alimentação no contexto contemporâneo e sistema alimentar. A reflexão e o debate sobre questões como comensalidade, globalização, culinária, comida e gênero, escolhas alimentares, consumo e sustentabilidade, propaganda e rotulagem de alimentos, bem como sobre outros componentes do sistema alimentar, permitem estabelecer uma visão crítica sobre alimentação e nutrição na atualidade.

O princípio de educação como processo permanente e gerador de autonomia e, também, como participação ativa e informada dos sujeitos (VI) se faz presente em todas as atividades dos três segmentos escolares. Isto se dá pela proposição de elementos para a incorporação da educação alimentar e nutricional de forma contínua e integrada às áreas de conhecimento e para a promoção de práticas alimentares autônomas e saudáveis. Além disso, esse princípio se materializa na abordagem problematizadora, que recorre a perguntas norteadoras do diálogo com os escolares, buscando explorar os diferentes saberes. Essa abordagem coloca em prática a perspectiva de que a educação alimentar e nutricional deve privilegiar os processos ativos, incorporar os conhecimentos e práticas populares, e contextualizar as realidades dos indivíduos ${ }^{16}$. Isso acontece por meio de atividades dialógicas, com propostas que estimulam uma reflexão crítica e a compreensão da relação do sujeito com o mundo. A reflexão fica mais clara para os sujeitos quando partimos de situações vivenciadas por eles ${ }^{41}$, como a valorização da diversidade alimentar de cada família presente, por exemplo, em seus quintais produtivos; a análise do rótulo de lanches levados pelos escolares; o levantamento dos alimentos que entram nas suas casas etc. A valorização da ludicidade e da utilização de expressões artísticas (massinha, corte e colagem, músicas, pinturas, jogos etc.) exemplificam estratégias de participação ativa dos sujeitos.

Cada atividade proposta enfoca pelo menos dois princípios em sua abordagem, podendo abarcar todos eles. Como exercício reflexivo sobre a tradução dos princípios do Marco para as atividades, analisaremos a abordagem de cada um deles na atividade A Escola na Feira, proposta para o Ensino Fundamental I, que aborda todos os princípios da seguinte forma: valorização da feira como um espaço de compra de alimentos in natura e minimamente processados e no diálogo entre meios de produção, abastecimento, comercialização e distribuição dos alimentos (princípios I e II); o enfoque da preservação da cultura alimentar com a pesquisa sobre alimentos típicos da região (III); discussão dos alimentos in natura como referência e na valorização das preparações culinárias típicas da região que têm como base esses alimentos (IV); diálogo reflexivo sobre os motivos pelos quais os estudantes nunca experimentaram alguns alimentos $(\mathrm{V})$; desdobramento da visita com proposta de conversa com feirantes e/ou produtores de alimentos (VI); visita à feira livre (VII), e conversa com agricultor (VIII). Já o IX se expressa no planejamento detalhado no item Organização Prévia e na avaliação por meio da elaboração, pela turma, de um desenho coletivo que registre a experiência vivida.

Os Cadernos favorecem o planejamento conjunto entre a saúde e a educação ao propor temas e estratégias de ação que encorajam a pactuação entre profissionais desses setores. As atividades propostas pretendem ir além de ações da saúde e da educação com abordagens tradicionais que, muitas vezes, não fazem sentido para as vidas dos sujeitos 42 . Ainda que seja um material com abrangência nacional, as atividades possibilitam a incorporação das diferentes realidades locais de contexto de 
vida dos escolares e de organização do currículo escolar. Essas duas perspectivas estão em consonância com o componente "planejamento" do princípio IX do Marco de Educação Alimentar e Nutricional, na medida em que contribuem para a definição de objetivos comuns entre saúde e educação no âmbito do PSE e de estratégias para alcançá-los, elementos fundamentais para uma prática de educação alimentar e nutricional mais efetiva e sustentável.

Em relação ao percurso metodológico, cabe comentar que, ao longo do processo de elaboração e publicação destes materiais, as DCN foram atualizadas em função da reorganização curricular que incorporou o atendimento em creche e em pré-escola à educação básica, e definiu o Ensino Fundamental de nove anos de escolaridade. Em especial, na Educação Infantil, a interação e a ludicidade foram experiências de aprendizagem valorizadas e aprofundadas nestas atualizações, a fim de resguardar o direito e a necessidade de brincar e o papel da escola junto à família, para fortalecer a autonomia da criança pequena. As mudanças caminharam no sentido da qualificação das diretrizes anteriores $18 \mathrm{e}$, assim, o conteúdo e a abordagem dos Cadernos permaneceram convergentes com as novas diretrizes.

Outro aspecto a ser comentado é que, em função dos prazos previstos para a entrega da série de materiais, não foi possível realizar um pré-teste de todas as atividades. No entanto, em sua maioria, estas foram construídas com base em atividades experimentadas em diversas ações de formação de estudantes da graduação em Nutrição e na prática de profissionais de saúde e de educação. Com o intuito de superar esta limitação, está sendo desenhado um estudo de avaliação do uso desses materiais. Está em andamento também o planejamento das atividades de difusão do material. Elas envolverão, entre outros, fóruns virtuais com gestores do PSE nos estados e municípios, além de outros atores estratégicos que atuam nas redes de saúde e de educação e que poderão difundir e encorajar o uso dos materiais.

Como fortaleza, destaca-se o envolvimento, no decorrer do projeto, de pedagogas experientes na prática da docência nos três segmentos, o que permitiu alcançar a consistência e a profundidade de articulação com o currículo pretendidas em sua concepção.

O desafio de produzir um material único para todo o Brasil constituiu-se em uma oportunidade para ousar. A estratégia utilizada para atingir essa intenção foi adotar um processo de elaboração dos materiais que envolveu a participação de atores de diferentes estados de todas as regiões do país e de uma abordagem, no material, que estimula sua adaptação à realidade local e às discussões levantadas pelos estudantes como ponto de partida para as atividades.

\section{Considerações finais}

A Matriz e os Cadernos contribuem para a incorporação do tema da alimentação e nutrição na escola por meio de ações de educação alimentar e nutricional que articulem as diferentes dimensões da alimentação aos conteúdos dos componentes curriculares de cada segmento, e sejam baseadas nos princípios do Marco de Educação Alimentar e Nutricional. Espera-se que essa proposta colabore para a superação da abordagem de alimentação e nutrição restrita aos componentes ciências e biologia, para a ampliação do repertório dos educadores sobre a temática de alimentação e nutrição e para sua inclusão no currículo de forma cotidiana e transversal.

A Matriz, que havia sido concebida como uma estratégia para organizar o pensamento e o processo de trabalho, ao final do percurso de elaboração dos materiais, se configurou como uma expressão teórica dessa construção de conhecimento, podendo ser elemento orientador da produção de outros materiais 43 e de projetos e práticas de educação alimentar e nutricional no ambiente escolar. Para além dos materiais produzidos, o exercício reflexivo deste artigo contribui para o amadurecimento do debate sobre educação alimentar e nutricional no currículo e no apoio à concretização dessa articulação.

Ao assumirmos uma compreensão ampliada da alimentação, foi possível elaborar um leque de atividades suficiente para viabilizar o diálogo com diferentes componentes curriculares e apresentar uma série de possibilidades de ação conjunta entre os educadores, sejam eles professores ou profissionais de saúde, e a comunidade escolar. Além disso, as atividades propostas se ancoram e, ao mesmo 


\section{Quadro 5}

Quantidade e exemplos de atividades segundo princípios do Marco de Referência de Educação Alimentar e Nutricional para Políticas Públicas (Marco de Educação Alimentar e Nutricional) e segmento escolar. Rio de Janeiro, Brasil, 2020.

\begin{tabular}{|c|c|c|c|}
\hline \multirow{3}{*}{$\begin{array}{l}\text { PRINCÍPIO DO MARCO DE } \\
\text { EDUCAÇÃO ALIMENTAR E } \\
\text { NUTRICIONAL }\end{array}$} & \multicolumn{3}{|c|}{ SEGMENTO ESCOLAR } \\
\hline & EDUCAÇÃO INFANTIL & $\begin{array}{l}\text { ENSINO FUNDAMENTAL I } \\
\text { (ANOS INICIAIS) }\end{array}$ & $\begin{array}{l}\text { ENSINO FUNDAMENTAL II } \\
\text { (ANOS FINAIS) }\end{array}$ \\
\hline & $\begin{array}{l}\text { NÚMERO DE ATIVIDADES } \\
\text { (EXEMPLO) }\end{array}$ & $\begin{array}{l}\text { NÚMERO DE ATIVIDADES } \\
\text { (EXEMPLO) }\end{array}$ & $\begin{array}{l}\text { NÚMERO DE ATIVIDADES } \\
\text { (EXEMPLO) }\end{array}$ \\
\hline $\begin{array}{l}\text { I. Sustentabilidade social, } \\
\text { ambiental e econômica }\end{array}$ & $\begin{array}{c}5 \\
\text { (plantio de sementes e mudas) }\end{array}$ & $\begin{array}{c}12 \\
\text { (fatores que influenciam as } \\
\text { práticas alimentares) }\end{array}$ & $\begin{array}{c}18 \\
\text { (impacto da produção e consumo de } \\
\text { alimentos no meio ambiente) }\end{array}$ \\
\hline $\begin{array}{l}\text { II. Abordagem do sistema } \\
\text { alimentar, na sua integralidade }\end{array}$ & $\begin{array}{c}5 \\
\text { (feira como espaço de alimentos } \\
\text { saudáveis) }\end{array}$ & $\begin{array}{c}12 \\
\text { (mudanças dos alimentos } \\
\text { em função do grau de } \\
\text { processamento) }\end{array}$ & $\begin{array}{c}16 \\
\text { (práticas cotidianas de consumo) }\end{array}$ \\
\hline $\begin{array}{l}\text { III. Valorização da cultura } \\
\text { alimentar local e respeito à } \\
\text { diversidade de opiniões e } \\
\text { perspectivas, considerando a } \\
\text { legitimidade dos saberes de } \\
\text { diferentes naturezas }\end{array}$ & $\begin{array}{c}10 \\
\text { (alimentos consumidos pelas } \\
\text { famílias) }\end{array}$ & $\begin{array}{c}22 \\
\text { (alimentos regionais) }\end{array}$ & $\begin{array}{c}24 \\
\text { (proteção à amamentação) }\end{array}$ \\
\hline $\begin{array}{l}\text { IV. A comida e o alimento } \\
\text { como referências; valorização } \\
\text { da culinária enquanto prática } \\
\text { emancipatória }\end{array}$ & $\begin{array}{c}17 \\
\text { (comidas típicas de festas } \\
\text { regionais) }\end{array}$ & $\begin{array}{c}27 \\
\text { (alimentos, preparações } \\
\text { culinárias, equipamentos } \\
\text { e utensílios em diferentes } \\
\text { gerações) }\end{array}$ & $\begin{array}{c}17 \\
\text { (comida e gênero) }\end{array}$ \\
\hline $\begin{array}{l}\text { V. A promoção do autocuidado e } \\
\text { da autonomia }\end{array}$ & $\begin{array}{c}25 \\
\text { (percepções corporais } \\
\text { e características das } \\
\text { personalidades) }\end{array}$ & $\begin{array}{c}29 \\
\text { (água na composição de } \\
\text { alimentos e do corpo humano) }\end{array}$ & $\begin{array}{c}24 \\
\text { (conceito de beleza e diversidade) }\end{array}$ \\
\hline $\begin{array}{l}\text { VI. A educação enquanto } \\
\text { processo permanente e gerador } \\
\text { de autonomia e participação ativa } \\
\text { e informada dos sujeitos }\end{array}$ & $\begin{array}{c}26 \\
\text { (vivência do preparo de } \\
\text { alimentos) }\end{array}$ & $\begin{array}{c}33 \\
\text { (produção de caderno de receita } \\
\text { da turma) }\end{array}$ & $\begin{array}{c}26 \\
\text { (elaboração de peça de } \\
\text { comunicação: slogan, música, vídeo, } \\
\text { poesia, carta aberta etc.) }\end{array}$ \\
\hline $\begin{array}{l}\text { VII. A diversidade nos cenários de } \\
\text { prática }\end{array}$ & $\begin{array}{c}8 \\
\text { (feira livre/sacolão/refeitório) }\end{array}$ & $\begin{array}{c}13 \\
\text { (praça/quintal/pátio) }\end{array}$ & $\begin{array}{c}14 \\
\text { (farmácias/supermercados/cozinha } \\
\text { da escola) }\end{array}$ \\
\hline VIII. Intersetorialidade & $\begin{array}{c}8 \\
\text { (parceria com Estratégia Saúde } \\
\text { da Família) }\end{array}$ & $\begin{array}{c}10 \\
\text { (conversa com agricultor, } \\
\text { agrônomo ou técnico agrícola) }\end{array}$ & $\begin{array}{c}11 \\
\text { (pesquisas junto ao Instituto do } \\
\text { Patrimônio Histórico e Artístico } \\
\text { Nacional sobre receitas e utensílios } \\
\text { que são patrimônio) }\end{array}$ \\
\hline $\begin{array}{l}\text { IX. Planejamento, avaliação e } \\
\text { monitoramento das ações }\end{array}$ & $\begin{array}{l}\text { As atividades são apresentadas } \\
\text { (organização prévia) para a execı } \\
\text { envolver os educandos nessa eta }\end{array}$ & $\begin{array}{l}\text { es estrutura de roteiro demonstra } \\
\text { ão da ação e enfatizando o diagnó } \\
\text { a, fortalecendo assim o cunho part } \\
\text { ência de Educação Alimentar e Nut }\end{array}$ & $\begin{array}{l}\text { do a importância do planejamento } \\
\text { stico local. Além de, em muitos casos, } \\
\text { cipativo recomendado pelo Marco de } \\
\text { ricional. }\end{array}$ \\
\hline
\end{tabular}

Fonte: elaborado pelas autoras (2020). 
tempo, estimulam a autonomia desses educadores, uma vez que a versatilidade do material permite sua adaptação à organização curricular de cada rede de ensino bem como aos contextos locais. Sendo assim, a iniciativa apresentada neste artigo fortalece as ações de educação alimentar e nutricional no âmbito da escola e apoia a relação entre saúde e educação, elemento estruturante do PSE.

\section{Colaboradores}

L. Maldonado, S. C. Farias, J. J. Damião, L. M. C. Castro, A. C. F Silva e I. R. R. Castro participaram da concepção do projeto, produção, análise e interpretação dos dados, redação e revisão do artigo.

\section{Informações adicionais}

ORCID: Luciana Maldonado (0000-0001-97187526); Silvia Cristina Farias (0000-0002-91173833); Jorginete de Jesus Damião (0000-0001-65913474); Luciana Maria Cerqueira Castro (00000003-2793-9950); Ana Carolina Feldenheimer da Silva (0000-0001-5554-8856); Inês Rugani Ribeiro de Castro (0000-0002-7479-4400).

\section{Agradecimentos}

A todos os profissionais de saúde e de educação que contribuíram para a elaboração desta série de materiais; às bolsistas de graduação em nutrição do Núcleo de Alimentação e Nutrição em Políticas Públicas, Instituto de Nutrição, Universidade do Estado do Rio de Janeiro, que atuaram no levantamento dos materiais complementares (Carta Acordo BR/LOA/1300081.001 - OPAS e CEPESC/ UERJ - Elaboração de Materiais de Apoio para Promoção da Alimentação Adequada e Saudável).

\section{Referências}

1. Secretaria de Atenção à Saúde, Ministério da Saúde. Política Nacional de Alimentação e Nutrição. Brasília: Ministério da Saúde; 2013.

2. Departamento de Atenção Básica, Secretaria de Atenção à Saúde, Ministério da Saúde. Guia alimentar para a população brasileira. 2a Ed. Brasília: Ministério da Saúde; 2014.

3. Departamento de Promoção da Saúde, Secretaria de Atenção Primária à Saúde, Ministério da Saúde. Guia alimentar para crianças brasileiras menores de 2 anos. Brasília: Ministério da Saúde; 2019.

4. Fundo Nacional de Desenvolvimento da Educação. Resolução no 06, de 08 de maio de 2020. Dispõe sobre o atendimento da alimentação escolar aos alunos da educação básica no âmbito do Programa Nacional de Alimentação Escolar - PNAE. Diário Oficial da União 2020; 12 mai.

5. Departamento de Atenção Básica, Secretaria de Atenção à Saúde, Ministério da Saúde. Matriz de ações de alimentação e nutrição na atenção básica de saúde. Brasília: Ministério da Saúde; 2009.

6. Secretaria Nacional de Segurança Alimentar e Nutricional, Ministério de Desenvolvimento Social e Combate à Fome. Marco de referência de educação alimentar e nutricional para as políticas públicas. Brasília: Ministério do Desenvolvimento Social e Combate à Fome; 2012.

7. Casemiro JP, Fonseca ABC, Secco FVM. Promover saúde na escola: reflexões a partir de uma revisão sobre saúde escolar na América Latina. Ciênc Saúde Colet 2014; 19:829-40.

8. Food and Agriculture Organization of the United Nations. School food and nutrition framework. Rome: Food and Agriculture Organization of the United Nations; 2019.

9. Carvalho FFB. A saúde vai à escola: a promoção da saúde em práticas pedagógicas. Physis (Rio J.) 2015; 25:1207-27. 
10. Silva CS, Bodstein RCA. Referencial teórico sobre práticas intersetoriais em promoção da saúde na escola. Ciênc Saúde Colet 2016; 21:1777-88

11. Brasil. Decreto Presidencial no 6.286, de 5 de dezembro de 2007. Institui o Programa Saúde na Escola - PSE, e dá outras providências. Diário Oficial da União 2007; 6 dez.

12. Brasil. Lei no 11.947 , de 16 de julho de 2009 . Dispõe sobre o atendimento de alimentação escolar e do Programa Dinheiro Direto na Escola aos alunos da educação básica; altera as Leis nos 10.880, de 9 de junho de 2004, 11.273, de 6 de fevereiro de 2006, 11.507, de 20 de julho de 2007; revoga dispositivos da Medida Provisória no 2.178-36, de 24 de agosto de 2001, e a Lei no 8.913, de 12 de julho de 1994; e dá outras providências. Diário Oficial da União 2009; 17 jun.

13. Brasil. Lei no 13.666 , de 16 de maio de 2018 . Altera a Lei no 9.394, de 20 de dezembro de 1996 (Lei de Diretrizes e Bases da Educação Nacional), para incluir o tema transversal da educação alimentar e nutricional no currículo escolar. Diário Oficial da União 2018; 17 mai.

14. Castro IRR. Desafios e perspectivas para a promoção da alimentação adequada e saudável no Brasil. Cad Saúde Pública 2015; 31:7-9.

15. Castro IRR, Castro LMC, Silva ACF, Gugelmin SA. A questão alimentar nas politicas públicas: cenário atual, desafios e perspectivas. In: Diez-Garcia RW, Mancuso AMC, organizadores. Mudanças alimentares e educação alimentar e nutricional. 2a Ed. Rio de Janeiro: Guanabara Koogan; 2017. p. 99-121.

16. Vasconcelos EM. A saúde nas palavras e nos gestos: reflexões da rede de educação popular e saúde. São Paulo: Hucitec; 2001.

17. Brasil. Lei no 9.394, de 20 de dezembro de 1996. Estabelece as diretrizes e bases da educação nacional. Diário Oficial da União 1996; 23 dez.

18. Conselho Nacional de Educação, Ministério da Educação. Base nacional comum curricular. Brasília: Ministério da Educação; 2018.

19. Secretaria de Educação Fundamental, Ministério da Educação e do Desporto. Referencial curricular nacional para a educação infantil. v.1. Brasília: Ministério da Educação; 1998.

20. Secretaria de Educação Fundamental, Ministério da Educação e do Desporto. Referencial curricular nacional para a educação infantil. v. 2. Brasília: Ministério da Educação; 1998.

21. Secretaria de Educação Fundamental, Ministério da Educação e do Desporto. Referencial curricular nacional para a educação infantil. v. 3. Brasília: Ministério da Educação; 1998.

22. Secretaria de Educação Básica, Ministério da Educação. Diretrizes curriculares nacionais para a Educação Infantil. Brasília: Ministério da Educação; 2010.

23. Secretaria de Educação Fundamental, Ministério da Educação. Parâmetros curriculares nacionais: primeiro e segundo ciclos do Ensino Fundamental. Introdução aos parâmetros curriculares nacionais. Brasília: Ministério da Educação; 1997.
24. Secretaria de Educação Fundamental, Ministério da Educação. Parâmetros curriculares nacionais: primeiro e segundo ciclos do Ensino Fundamental. Introdução aos parâmetros curriculares nacionais. Brasília: Ministério da Educação; 1998.

25. Conselho Nacional da Educação, Secretaria de Educação Continuada, Alfabetização, Diversidade e Inclusão, Secretaria de Educação Básica, Ministério da Educação. Diretrizes curriculares nacionais gerais da educação básica. Brasília: Ministério da Educação; 2013.

26. Greenwood SA, Fonseca AB. Espaços e caminhos da educação alimentar e nutricional no livro didático. Ciênc Educ (Bauru) 2016; 22:201-18.

27. Santos AM, Alves TS. Revisão sistemática sobre educação alimentar e nutricional: sujeitos, saberes e práticas em diferentes cenários. Revista Saúde.com 2015; 11:425-42.

28. Ramos FP, Santos LAS, Reis ABC. Educação alimentar e nutricional em escolares: uma revisão de literatura. Cad Saúde Pública 2013; 29:2147-61.

29. Viana MR, Neves AS, Camargo Jr. KR, Prado $\mathrm{SD}$, Mendonça ALO. A racionalidade nutricional e sua influência na medicalização da comida no Brasil. Ciênc Saúde Colet 2017; $22: 447-56$

30. Monteiro CA, Cannon G, Levy RB, Moubarac JC, Louzada MLC, Rauber F, et al. Ultra-processed foods: what they are and how to identify them. Public Health Nutr 2019; 22:936-41.

31. Nazmi A, Tseng M, Robinson D, Neill D, Walker J. A nutrition education intervention using NOVA is more effective than MyPlate alone: a proof-of-concept randomized controlled trial. Nutrients 2019; 11:2965.

32. Câmara Interministerial de Segurança Alimentar e Nutricional. Plano Nacional de Segurança Alimentar e Nutricional: 2012/2015. Brasília: Câmara Interministerial de Segurança Alimentar e Nutricional; 2011.

33. High Level Panel of Experts on Food Security and Nutrition. Nutrition and food systems: a report by the High Level Panel of Experts on Food Security and Nutrition of the Committee on World Food Security. Rome: Committee on World Food Security; 2017.

34. Mills S, White M, Brown H, Wrieden W, Kwasnicka D, Halligan J, et al. Health and social determinants and outcomes of home cooking: A systematic review of observational studies. Appetite 2017; 111:116-34.

35. Departamento de Atenção Básica, Secretaria de Atenção à Saúde, Ministério da Saúde. Alimentos regionais brasileiros. 2a Ed. Brasília: Ministério da Saúde; 2015.

36. Moreira SA. Alimentação e comensalidade: aspectos históricos e antropológicos. Ciênc Cult (São Paulo) 2010; 62:23-6. 
37. Brasil. Decreto no 7.272 , de 25 de agosto de 2010. Regulamenta a Lei no 11.346 , de 15 de setembro de 2006, institui a Política Nacional de Segurança Alimentar e Nutricional - PNSAN, estabelece o parâmetro para a elaboração do Plano Nacional de Segurança Alimentar e Nutricional e dá outras providências. Diário Oficial da União 2010; 25 ago.

38. Schilder P. A imagem do corpo: as energias construtivas da psique. São Paulo: Martins Fontes; 1981.

39. Biroli F. Gênero e desigualdades: os limites da democracia no Brasil. São Paulo: Boitempo; 2018.

40. Ministério do Meio Ambiente. Consumismo infantil: na contramão da sustentabilidade. Brasília: Ministério do Meio Ambiente; 2014. (Cadernos de Consumo Sustentável, 3).
41. Freire P. Pedagogia da autonomia: saberes necessários à prática educativa. 58a Ed. São Paulo: Paz e Terra; 1997.

42. Santos LAS. O fazer educação alimentar e nutricional: algumas contribuições para reflexão. Ciênc Saúde Colet 2012; 17:455-62.

43. Castro SFF, Melgaço MB, Souza VMG, Santos KS. Convergência de políticas públicas educacionais na promoção da alimentação adequada e saudável. Rev Panam Salud Pública 2019; 43:e96. 


\section{Abstract}

Materials were prepared for schoolteachers and healthcare workers to support permanent initiatives in food and nutrition education in schools, integrated into the curriculum. The article presents the matrix of food and nutrition topics that served as the basis for producing these materials (Matrix) and the convergence between the approach adopted in the activities in the Activity Manuals comprising the series of materials and food dimensions, the principles of the Framework for Food and Nutrition Education for Public Policies (Framework for Food and Nutrition Education), and the Brazilian National Curriculum Guidelines for basic education. The Matrix allowed designing educational activities that foster an expanded approach to food and nutrition which is simultaneously crosscutting and integrated into the curriculum. The activities allowed dialogue with various components of the curriculum and linkage between them. The activities' convergence with the Framework for Food and Nutrition Education was expressed in the contextualization of food practices in the schoolchildren's territories and realities; in the problematical approach, which encourages critical thinking and the promotion of autonomy, both for educators and schoolchildren; and intersector planning through topics and action strategies that encourage collaboration between healthcare professionals and teachers. The initiative presented in this article thus strengthens the actions by food and nutrition education in schools and can expand teachers' repertoire in food and nutrition and contribute to its crosscutting and routine inclusion in the curriculum.

Feeding Behavior; School Health Services; Teaching Materials

\section{Resumen}

Buscando apoyar iniciativas de educación alimentaria y nutricional en la escuela, continuas e integradas en el currículo, se elaboró una serie de materiales de apoyo para profesionales de educación y de salud. El artículo presenta la matriz de temáticas de alimentación y nutrición, que sirvió de base para la construcción de estos materiales (Matriz), $y$ presenta la convergencia entre el abordaje adoptado en las actividades de los Cadernos de Actividades, que componen la serie de materiales y las dimensiones de la alimentación, los principios del Marco de Referencia de Educación Alimentaria y Nutricional para Políticas Públicas (Marco de Educación Alimentaria y Nutricional), y las directrices curriculares nacionales para la educación básica. La Matriz permitió la concepción de actividades educativas que dan la oportunidad de un abordaje ampliado sobre alimentación y nutrición y, al mismo tiempo, transversal y articulado en el currículo. Las actividades posibilitaron el diálogo con diferentes componentes curriculares y la coordinación entre ellos. La convergencia de las actividades con el Marco de Educación Alimentaria y Nutricional se expresó en la contextualización de las prácticas alimentarias en los territorios $y$ realidades de los escolares; en el abordaje problematizador, que estimula el pensamiento crítico y la promoción de autonomía, tanto de educadores como de escolares; $y$ en la planificación intersectorial mediante temas y estrategias de acción, que fomentan los acuerdos entre profesionales de salud $y$ de educación. Siendo así, la iniciativa presentada en este artículo fortalece las acciones de educación alimentaria y nutricional en el ámbito de la escuela y puede colaborar en la ampliación del repertorio de los educadores sobre la temática de alimentación y nutrición, así como en su inclusión dentro del currículo de forma cotidiana y transversal.

Conducta Alimentaria; Servicios de Salud

Escolar; Materiales de Enseñanza
Recebido em 04/Jun/2020

Versão final representada em 20/Out/2020

Aprovado em 26/Out/2020 